\title{
Immune reconstitution inflammatory syndrome in a patient with progressive multifocal leukoencephalopathy
}

\author{
Lokesh Shahani, ${ }^{1}$ Minal Shah, ${ }^{1}$ Shahriar Tavakoli-Tabasi ${ }^{1,2}$
}

${ }^{1}$ Department of Internal Medicine, Baylor College of Medicine, Houston, Texas, USA 2Department of Medicine, Michael E DeBakey Veterans Affairs Medical Center, Houston, Texas, USA

\section{Correspondence to} Dr Lokesh Shahani, lokesh83@hotmail.com

Accepted 20 May 2015
To cite: Shahani L, Shah M, Tavakoli-Tabasi S. BMJ Case Rep Published online: [please include Day Month Year] doi:10.1136/bcr-2014207325

\section{SUMMARY}

Progressive multifocal leukoencephalopathy (PML) is a severe opportunistic infection of the central nervous system. A 52-year-old man with HIV infection, recently started on antiretroviral therapy, presented with symptoms of mental cloudiness, blurry vision and ataxia. MRI of the brain showed nodular perivascular space enhancement with surrounding vasogenic oedema and midline shift. A lumbar puncture revealed noninflammatory cerebrospinal fluid and was positive for JC virus. As the patient developed worsening symptoms in the setting of initiation of antiretroviral therapy with immune recovery, a diagnosis of JC virus-associated immune reconstitution inflammatory syndrome (IRIS) was made. With recent literature on the use of CCR5 antagonist maraviroc in $\mathrm{PML}$, our patient was started on maraviroc and noted to have improvement in PML IRIS. This is the first case of an HIV-positive patient successfully treated for PML IRIS with maraviroc, as verified by our literature review; also, our case has clinical implications in improving outcome in PML IRIS.

\section{BACKGROUND}

Progressive multifocal leukoencephalopathy (PML) is a severe, and at times fatal, opportunistic infection of the central nervous system. Primary infection occurs during childhood and is asymptomatic in most patients. JC virus, the causative agent of PML, remains latent; however, it can reactivate during a period of immunosuppression such as with HIV infection. While PML most often presents with motor deficits, visual disturbances and cognitive impairment, initial symptoms can be mild and subacute, therefore diagnosis can be missed early in the disease.

Highly active antiretroviral therapy (HAART) has significantly improved survival of patients with AIDS and PML, ${ }^{1}$ and is currently considered standard therapy for AIDS-related PML. However, in some instances, paradoxical worsening of clinical and of radiological features results from an inflammatory syndrome as a consequence of HAART-induced restoration of the immune system. We report a case of PML immune reconstitution inflammatory syndrome, where a patient worsened neurologically after initiation of HAART.

\section{CASE PRESENTATION}

A 52-year-old man with HIV infection presented to his primary care clinic with difficulty in walking. He had been diagnosed with HIV 3 months earlier at an outside hospital after an admission for pneumonia. He had been started on antiretroviral therapy with emtricitabine, tenofovir and ritonavirboosted darunavir 2 months prior to this presentation. He had responded well to the regimen, with an improvement in his CD4 count from 67 to 153 cells $/ \mu \mathrm{L}$ and suppression of his viral load from 1530 to 71 copies $/ \mathrm{mL}$.

Three weeks prior to his current presentation, he began to experience mental cloudiness and blurry vision, and had difficulty with balance and walking. On further questioning, the patient mentioned having mild cognitive difficulties for the past 5 months. His neurological examination was remarkable for a left homonymous hemianopsia.

\section{INVESTIGATIONS}

A CT of the brain showed a hypodense lesion lateral to the anterior aspect of the right-sided lenticular nucleus associated with oedema and midline shift. MRI of the brain was performed to characterise the mass further. The MRI with contrast showed nodular perivascular space enhancement throughout the supratentorium with greater involvement in the right hemisphere. There was surrounding vasogenic oedema, mass effect and a $3 \mathrm{~mm}$ leftward midline shift (figure 1).

A lumbar puncture was performed and revealed non-inflammatory cerebrospinal fluid (CSF) with a negative Gram stain and culture. The Cerebrospinal fluid PCR was positive for JC virus (6649 copies/ $\mathrm{mL}$ ) and negative for cytomegalovirus, herpes simplex virus (HSV) 1, HSV-2, varicella-zoster virus, Epstein-Barr virus, Cryptococcus and Toxoplasma. The flow cytometry performed on the fluid showed increased CD8 + T cells with complete absence on the CD4 cells.

\section{OUTCOME AND FOLLOW-UP}

As the patient developed worsening symptoms in the setting of initiation of antiretroviral therapy with immune recovery, a diagnosis of JC virus-associated immune reconstitution inflammatory syndrome (IRIS) was made. With recent literature on the use of CCR5 antagonist maraviroc in PML, ${ }^{2} 3$ the patient was started on oral maraviroc $150 \mathrm{mg}$ twice a day. A Trofile Assay (Monogram Biosciences) had shown the HIV-1 to be exclusively CCR5 tropic. Two months later, a repeat MRI showed improvement in the lesion (figure 2); the patient reported complete resolution of his neurological symptoms. Maraviroc was continued in this 


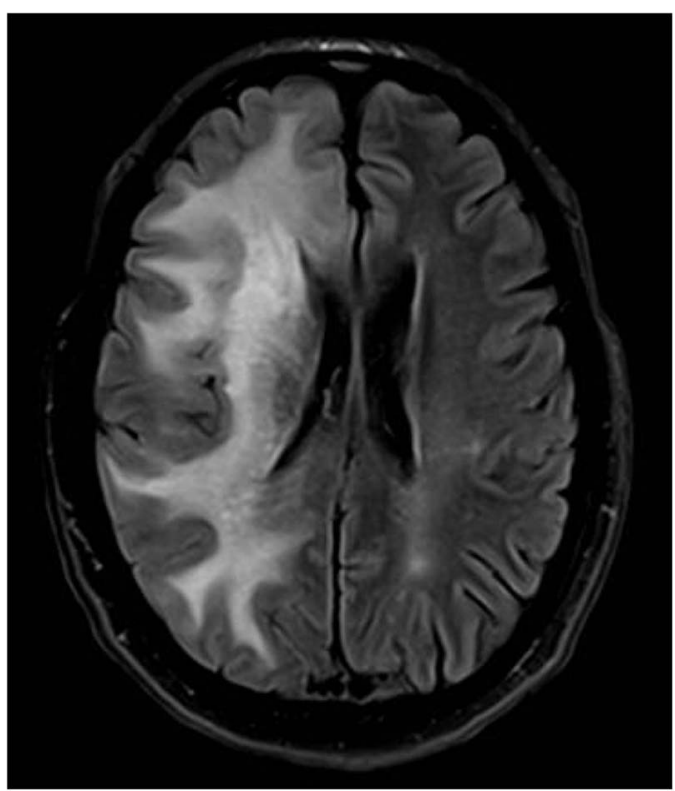

Figure $1 \mathrm{MRI}$ of the brain at presentation showing right-sided nodular perivascular space enhancement throughout the supratentorium with surrounding vasogenic oedema, mass effect and a $3 \mathrm{~mm}$ leftward midline shift.

patient for a year, when his MRI had shown complete resolution of the previously observed lesions.

\section{DISCUSSION}

Although the patient had some baseline cognitive impairment, the neurological deficits significantly worsened after the initiation of HAART. This is consistent with the unmasking form of IRIS to PML, where subtle clinical symptoms of PML worsened after initiation of HAART and with laboratory evidence of

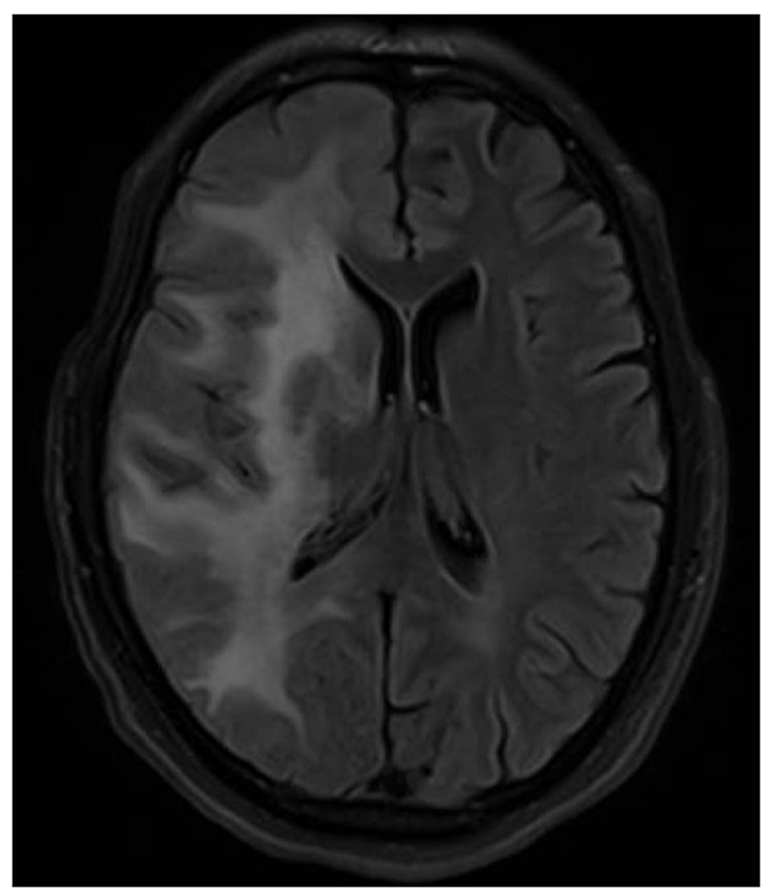

Figure $2 \mathrm{MRI}$ of the brain after 2 months, showing improvement in the lesion. improved immune status. The key points that differentiate PML IRIS from worsening of the primary infection include clinical, radiological and pathological features. Clinically, the reported patient with mild cognitive difficulties worsened neurologically 8 weeks after starting HAART and with laboratory evidence of immune recovery. Other reports have described patients being diagnosed with PML IRIS between 1 week and 26 months after initiation of HAART, with a median time of 7 weeks. Furthermore, $80 \%$ of these patients developed PML IRIS within 12 weeks of initiation of HAART. ${ }^{4}$ Factors predictive of development of IRIS in previous studies include antiretroviral drug naivety, low CD4 count $\left(50\right.$ cells $\left./ \mathrm{mm}^{3}\right)$, and rapid immune recovery indicated by a prompt decrease in HIV plasma viral load. $^{5}$

Radiologically, primary PML brain lesions on T1-weighted MRI of the brain are hypointense, whereas T2-weighted images are hyperintense. ${ }^{6}$ Lesions are located predominantly in the subcortical white matter and are asymmetric. They are usually not enhanced after intravenous contrast injection and are not associated with swelling or mass effect. However, contrast enhancement along with oedema and mass effect, denoting blood-brain barrier disruption secondary to the inflammatory process, is seen in $44 \%$ to $57 \% \%^{4}$ of the PML IRIS cases supporting our diagnosis.

CD8 + T lymphocytes form the majority of cytotoxic cells, and are present only in small numbers within the normal CNS. ${ }^{8}$ However, in patients with PML IRIS, there is a strong cellular immune response mediated by JC virus-specific CD8 + cytotoxic $\mathrm{T}$ lymphocytes (CTL), which are instrumental in preventing disease progression. ${ }^{9}$ At times, CD8 + CTL responses may be so intense that $\mathrm{CD} 8+$ outnumber CD4 $+\mathrm{T}$ lymphocytes and cause significant neurotoxicity. There was a hint of the same in our patient, where the CSF had increased CD8 + T cells and CD4+ $\mathrm{T}$ were absent; however, a biopsy of the lesion would be more definitive for this phenomenon.

The use of steroids, especially when there are signs of impending brain herniation, ${ }^{10}$ has been recommended by some experts based on case reports; however, there are no randomised clinical trials to support such a recommendation. Use of cytarabine, acyclovir, cidofovir, chlorpromazine, mirtazapine, interleukin 2 , interferon $\beta$ and mefloquine has been reported in the literature. ${ }^{1}$ Two studies examining the use of cidofovir showed neither survival benefit, nor improvement in PML-related residual disability at 12 months. ${ }^{11}$ Similarly, the use of systemic or intrathecal cytosine arabinoside did not improve patient survival. ${ }^{13}{ }^{14}$ An antimalarial drug, mefloquine had initially shown some efficacy in PML, ${ }^{15}{ }^{16}$ however, a randomised open label study showed mefloquine had no evidence of anti-JC virus activity. ${ }^{17}$

PML has been clinically associated with the appearance of chemokine receptor (CCR) $7+$ monocytes in peripheral blood and a simultaneous decrease in the number of CCR5 + monocytes. Interestingly, the disappearance of peripheral CCR7+ monocytes and reappearance of CCR5 + in peripheral blood coincide with the onset of IRIS. ${ }^{2}$ This indirect implication of CCR5 + $\mathrm{T}$ cells in IRIS pathophysiology has been carried forward and CCR5 antagonist maraviroc has been used in the treatment of PML IRIS. A recent case report of PML IRIS in an HIV-negative patient demonstrated that maraviroc was associated with a selective decrease in CCR5 + immune cells in the CSF, with simultaneous clinical improvement. These findings suggest that maraviroc functionally inhibits CCR5-dependent immune cell trafficking into the central nervous system. ${ }^{3}$ Based on the above literature, our patient was started on maraviroc, 
and noted to have improvement in his PML IRIS. In our literature review, this is the first case of an HIV-positive patient successfully treated for PML IRIS with maraviroc. This case may have clinical implications as maraviroc can be used to augment the current HIV regimen and, at the same time, improve the outcome of PML IRIS. However, more clinical experience, possibly in the form of controlled studies, is needed to confirm such a conclusion.

\section{Learning points}

- Highly active antiretroviral therapy has significantly improved survival of patients with AIDS and progressive multifocal leukoencephalopathy (PML) and is currently considered standard therapy for AIDS-related PML.

- Immune reconstitution inflammatory syndrome is a clinical entity characterised by an excessive inflammatory response to a pre-existing antigen or pathogen and a paradoxical deterioration in clinical status after initiation of antiretroviral therapy.

- PML immune reconstitution inflammatory syndrome (IRIS) has been clinically associated with the disappearance of peripheral CCR7+ monocytes and reappearance of CCR5+ in peripheral blood; hence the use of CCR5 antagonist maraviroc has been proposed in the treatment of PML IRIS.

Competing interests None declared.

Patient consent Obtained.

Provenance and peer review Not commissioned; externally peer reviewed.

\section{REFERENCES}

1 Marzocchetti A, Tompkins T, Clifford DB, et al. Determinants of survival in progressive multifocal leukoencephalopathy. Neurology 2009;73:1551-8.
2 Schwab N, Höhn KG, Schneider-Hohendorf T, et al. Immunological and clinical consequences of treating a patient with natalizumab. Mult Scler 2012;18:335-44.

3 Giacomini PS, Rozenberg A, Metz I, et al. Maraviroc and JC virus-associated immune reconstitution inflammatory syndrome. $N$ Engl J Med 2014;370:486-8.

4 Tan CS, Koralnik IJ. Progressive multifocal leukoencephalopathy and other disorders caused by JC virus: clinical features and pathogenesis. Lancet Neurol 2010;9:425-37

5 Shelburne SA, Visnegarwala F, Darcourt J, et al. Incidence and risk factors for immune reconstitution inflammatory syndrome during highly active antiretroviral therapy. AIDS 2005;19:399-406.

6 Whiteman ML, Post MJ, Berger JR, et al. Progressive multifocal leukoencephalopathy in 47 HIV-seropositive patients: neuroimaging with clinical and pathologic correlation. Radiology 1993;187:233-40.

7 Harrison DM, Newsome SD, Skolasky RL, et al. Immune reconstitution is not a prognostic factor in progressive multifocal leukoencephalopathy. J Neuroimmunol 2011;238:81-6.

8 Neumann H, Medana IM, Bauer J, et al. Cytotoxic T lymphocytes in autoimmune and degenerative CNS disease. Trends Neurosci 2002;25:313-19.

9 Du Pasquier RA, Clark KW, Smith PS, et al. JCV-specific cellular immune response correlates with a favorable clinical outcome in HIV-infected individuals with progressive multifocal leukoencephalopathy. J Neurovirol 2001;7:318-22.

10 Tan K, Roda R, Ostrow L, et al. PML-IRIS in patients with HIV infection: clinical manifestations and treatment with steroids. Neurology 2009;72:1458-64.

11 De Luca A, Ammassari A, Pezzotti $P$, et al. Cidofovir in addition to antiretroviral treatment is not effective for AIDS-associated progressive multifocal leukoencephalopathy: a multicohort analysis. AIDS 2008;22:1759-67.

12 Marra CM, Rajicic N, Barker DE, et al. A pilot study of cidofovir for progressive multifocal leukoencephalopathy in AIDS. AIDS 2002;16:1791-7.

13 De Luca A, Giancola ML, Cingolani A, et al. Clinical and virological monitoring during treatment with intrathecal cytarabine in patients with AIDS-associated progressive multifocal leukoencephalopathy. Clin Infect Dis 1999;28:624-8.

14 Hall CD, Dafni U, Simpson D, et al. Failure of cytarabine in progressive multifocal leukoencephalopathy associated with human immunodeficiency virus infection. AIDS Clinical Trials Group 243 Team. N Engl J Med 1998;338:1345-51.

15 Beppu M, Kawamoto M, Nukuzuma S, et al. Mefloquine improved progressive multifocal leukoencephalopathy in a patient with systemic lupus erythematosus. Intern Med 2012;51:1245-7.

16 Moenster RP, Jett RA. Mirtazapine and mefloquine therapy for progressive multifocal leukoencephalopathy in a patient infected with human immunodeficiency virus. Am J Health Syst Pharm 2012;69:496-8.

17 Clifford DB, Nath $A$, Cinque $P$, et al. A study of mefloquine treatment for progressive multifocal leukoencephalopathy: results and exploration of predictors of PML outcomes. J Neurovirol 2013;19:351-8.

Copyright 2015 BMJ Publishing Group. All rights reserved. For permission to reuse any of this content visit http://group.bmj.com/group/rights-licensing/permissions.

BMJ Case Report Fellows may re-use this article for personal use and teaching without any further permission.

Become a Fellow of BMJ Case Reports today and you can:

- Submit as many cases as you like

- Enjoy fast sympathetic peer review and rapid publication of accepted articles

- Access all the published articles

- Re-use any of the published material for personal use and teaching without further permission

For information on Institutional Fellowships contact consortiasales@bmjgroup.com

Visit casereports.bmj.com for more articles like this and to become a Fellow 